\title{
INFLUÊNCIAS ACERCA DA COVID-19 ENTRECORTADAS PELAS INTERFACES DA HIPERMODERNIDADE NA FACULDADE DE PEDAGOGIA DA UNIRV
}

\author{
INFLUENCES ABOUT COVID-19 CUT BY HIPERMODERNITY INTERFACES IN \\ UNIRV'S PEDAGOGY FACULTY
}

José Reinaldo Araújo Quinteiro ${ }^{1}$
Rosimeire Soares da Silva ${ }^{2}$

\begin{abstract}
Resumo
A educação não consiste em um advento fora da sociedade, pois está imbricada em todas as esferas das relações humanas. Nessa via, este artigo visa apresentar como ocorreu a adesão ao ensino não presencial na educação superior goiana frente ao distanciamento social e a reinvenção da prática pedagógica na sociedade hipermoderna, tomando como âncora de estudo a Faculdade de Pedagogia da UniRV. Para tanto, questiona-se: Como a hipermodernidade se materializa na educação na educação superior goiana? Quais são as influências acerca da Covid-19 entrecortadas pelas interfaces hipermodernas para a reinvenção da prática pedagógica frente ao distanciamento social de 2020? Como reagiram os sujeitos da educação superior? No que tange à metodologia de pesquisa, busca-se, na relação com o objeto, descrever quais são esses processos e influências na instituição observada. Os procedimentos técnicos, deste estudo, são pautados em: documentos que regimentaram o distanciamento social em Goiás, além de leituras bibliográficas por meio das quais se alude ao conceito de sociedade hipermoderna e, por fim, ex-post-facto com vistas aclarar como a faculdade incorporou a aula não presencial em momento de crise sanitária.
\end{abstract}

Palavras-Chave: Hipermodernidade; Educação superior; Prática pedagógica.

\begin{abstract}
Education is not an advent outside of society, as it is interwoven in all spheres of human relations. In this way, this article aims to present how adherence to non-face-to-face teaching in Goiás higher education occurred in the face of social detachment and the reinvention of pedagogical practice in hypermodern society, taking the UniRV Faculty of Pedagogy as the study anchor. Therefore, ask yourself: How does hypermodernity materialize in higher education in Goiás? What are the influences on Covid-19 interrupted by hypermodern interfaces for the reinvention of pedagogical practice in the face of the social distance of 2020? How did higher education subjects react? Regarding the research methodology, it is sought, in relation to the object, to describe what these processes and influences are, in the observed institution. The technical procedures of this study will be based on: documents that regulated social distance in Goiás, in addition to bibliographic readings through which the concept of hypermodern society is alluded to and, finally, ex-post-facto in order to clarify how the faculty incorporated non-classroom classes in times of health crisis.
\end{abstract}

\footnotetext{
1 Doutor em Ciências da Religião pela Pontifícia Universidade Católica de Goiás. Professor na Universidade de Rio Verde e na Rede Estadual de Educação do Estado de Goiás.

E-mail: josereinaldoquinteiro@yahoo.com.br

ORCID: https://orcid.org/0000-0002-0317-5952

2 Mestra em Letras pela Pontifícia Universidade Católica de Goiás. Professora na Faculdade Almeida Rodrigues e na Rede Estadual de Educação do Estado de Goiás.

E-mail: rosimeiresoares34@gmail.com
} 
Key words: Hypermodernity; College education; Pedagogical practice.

\section{Introdução}

O calendário acadêmico do ano letivo de 2020 da educação superior de Goiás sofreu alterações quando as autoridades da saúde do Estado emitiram uma nota com sugestão para que fossem suspensas as aulas presenciais (em todas as redes e níveis de ensino) como medida de prevenção contra a disseminação do novo coronavírus ${ }^{3}$.

E, como a educação é um ato político ${ }^{4}$, este estudo objetiva apresentar o processo de adesão ao ensino não presencial da educação superior goiana frente ao distanciamento social e a reinvenção da prática pedagógica na sociedade hipermoderna, tomando como âncora de estudo o curso de Pedagogia da UniRV. Esta produção se justificativa pela viabilidade de se trazer à tona esse fenômeno de avanço ${ }^{5}$ educacional ocorrido em Goiás, ao passo que, em um pequeno período de tempo, a prática pedagógica do ensino superior passou a ocupar espaços de plataformas virtuais e acessos à educação por aulas não presenciais.

No que tange à metodologia de pesquisa, busca-se, na relação com o objeto, descrever os passos percorridos e desafios, na instituição observada. Os procedimentos técnicos deste estudo serão pautados em: documentos que

\footnotetext{
${ }^{3}$ Para conter ou controlar a propagação da Covid-19 (doença respiratória causada pelo Novo Coronavírus) as autoridades constituídas baixaram decretos, limitando o convívio social; as pessoas foram orientadas a permanecerem em seus lares, a usarem máscaras quando saíssem à rua e, ao retornarem aos seus lares, deveriam ser vigilantes à assepsia das mãos, dos calçados, das vestimentas e dos alimentos adquiridos para o consumo.

4 O Governo Ronaldo Caiado apresentou, em 10 fevereiro de 2020, o Plano estadual de contingência para o enfrentamento da infecção humana pelo novo Coronavírus (2019-nCoV) em que contém um histórico, a partir de 31 de dezembro de 2019, sobre o surgimento da doença na cidade de Wuhan, província de Hubei, na China; demonstra as características do novo vírus, e as medidas a serem tomadas para conter a propagação no Estado. A partir desse documento, sucessivas notas técnicas foram publicadas, como: Nota Técnica n : 5/2020, de 03 de abril, prorroga a "interrupção das atividades educacionais presenciais em todas as escolas, faculdades e universidades, das redes de ensino pública e privada, pelo período de 60 (sessenta) dias, a partir de 05/04/2020"; Resolução 02/2020 do Conselho Estadual de Educação (CEE) que dispõe sobre o regime especial de aulas não presenciais em todos os níveis à distância, mediante plataformas tecnológicas.

${ }^{5}$ Segundo o historiador brasileiro Leandro Karnal, em programa de debate da CNN Brasil, no dia 18 de abril e 2020, Guerras, Revoluções e Pandemias são acontecimentos históricos que aceleram e modificam processos sociais e políticas em curso.
} 
regimentaram o distanciamento social em Goiás, além de leituras bibliográficas por meio da qual se alude ao conceito de sociedade hipermoderna e, por fim, ex-postfacto com vistas aclarar como a instituição incorporou a aula não presencial em momento de crise sanitária.

Para tanto, este artigo está dividido em três subtópicos. No primeiro, apresentase o conceito e a descrição da presença da hipermodernidade - de Gilles Lipovetsky6. Assim, tomando como suporte essa teoria, serão explicitadas características dessa sociedade hipermoderna o que pode ter impulsionado a reinvenção das práticas pedagógicas nessa faculdade goiana.

No segundo momento, será feita exposição de como a Faculdade de Pedagogia da UniRV, locus deste estudo, sofreu influências da Covid-19. Para isso, registrar-se-ão os processos que regimentaram a adesão do ensino não presencial ao passo que se buscará perceber em que medida os sujeitos da pesquisa estavam de posse dos instrumentos para enfrentarem essa crise e ao mesmo tempo em que sua zona de conforto foi desconstruída, pois, talvez, não se pensava, a priori, em utilizálos. Com essas especificidades, serão registradas as movimentações internas para atender à demanda de uma nova proposta de educação, reinventando-se.

Por fim, o conceito de hipermodernidade entrará em voga para sustentar que é possível os atores envolvidos caminharem juntos (como progressistas, tradicionais e ou "tecnológicos") com os desacertos e os acertos dentro do processo ensinoaprendizagem.

Portanto, serão considerados os fatos relacionados à Covid-19 e suas influências que que entrecortam o fenômeno social a partir da modernidade em transição para hipermodernidade presente na Faculdade de Pedagogia da UniRV.

\section{A hipermodernidade: conceitos e percepções}

\footnotetext{
${ }^{6}$ Filósofo contemporâneo, estudioso da Hipermodernidade. Nasceu em 1944, em Millau, na França. É sociólogo e professor de Filosofia em Grenoble (França) é autor de várias obras publicadas pela grande editora francesa Gallimard.
} 
O século XXI é constituído pela transição da modernidade para a hipermodernidade. Esse "hiper" interage com todas as esferas das relações humanas, a se destacar: a artística, a política, a social e a econômica. Na atual conjuntura, essas categorias consistem em espaços que estão em constantes ressignificações e estão intrinsecamente ligadas às questões do capitalismo e às diversas implicações sociais desse regime, engendrando ações embebidas de novas necessidades.

À luz da filosofia do francês Gilles Lipovetsky, a hipermodernidade se faz presente em nossa sociedade a partir da década de 80 , mas registra-se que esse conceito, antes chamado pelo próprio filósofo de pós-modernidade, foi "atualizado" e consiste em um tempo em que o excesso ${ }^{7}$ e o vazio ${ }^{8}$ se enfrentam em um combate gerador de nova autonomia, novas liberdades, novas angústias e novas perspectivas. Para esse estudioso, há, também, novas formas de a sociedade se organizar, sendo com o mínimo de coerção e mais escolha, gerando a individualidade como recurso de desprendimento a fim de promover pensamento fora da estrutura socializante (LIPOVETSKY, 2004).

Para Lipovetsky e Serroy (2009), toda sociedade busca, de uma forma ou de outra, instaurar-se e criar sua identidade em um determinado espaço ideológico e geográfico. Para isso, segundo os autores, existe um constante movimento para a estilização do mundo, singularizando uma época e/ou uma sociedade. Assim, "As grandes estruturas socializantes perdem autoridade, as grandes ideologias já estão em expansão, os projetos históricos não mobilizam mais" Lipovetsky (2004, p. 23), instalando-se a "Era do Vazio", na qual, normalmente, se adaptam as relações sociais políticas e econômicas, mas de forma mais intensa e polarizada.

Além disso, registra-se o empoderamento do sujeito na perspectiva da hipermodernidade. Segundo Lipovetsky e Serroy (2009), o indivíduo, nessa era, é emancipado e mais informado, todavia é, também, mais desestruturado; não tem fé no futuro revolucionário e se adapta com facilidade a quaisquer situações e mercado. Tais características, para os filósofos, são reflexos da democratização política e

\footnotetext{
${ }^{7}$ A modernidade elevada à potência máxima (LIPOVETSKY; SERROY, 2009).

${ }^{8}$ Segundo Lipovetsky (2005), o desprendimento dos eixos estabilizantes, como família, política, igreja, impulsionou o homem a adquirir autonomia, o que engendrou o hiperindividualismo. Isso culminou em um vazio, permeado uma angústia por meio do qual se buscam, no consumo, novas construções e novas identidades sociais.
} 
econômica o que, de certa forma, abriu espaço para o capitalismo e este, com objetivo de ganhar espaço, difunde ideal de prazer, seja consumindo produto ou serviço, fortalecendo um ideário de cultura de massa e de interação tecnológica.

Registra-se que esse empoderamento está associado aos diversos acessos que o cidadão comum pode ter, seja virtual, pela TV (marketing) e ao fato da eclosão da cultura de massa não ser capaz de inserir esse indivíduo ao discernimento e à criticidade, no que se refere ao consumo e à arte.

Tais reflexões gravitam em torno da completa emancipação do indivíduo, bem como a democratização e acessos às plataformas virtuais por meio da internet, bem como da hiperindividualidade, uma vez que, com isso, os indivíduos se autonomizaram e se tornaram independentes inclusive de ideais de grupo, ideais políticos e culturais.

Assim, o homem hipermoderno, recolhido em si próprio, se apresenta em "O desapossamento, a dessubstanciação do indivíduo, longe de se circunscrever ao trabalho, ao poder, invade agora a sua unidade, a sua vontade, a sua hilaridade", gerando identidade autônoma. Mas, ainda para Lipovetsky e Charles (2004, p. 18), "É essencial compreender que todo ganho de autonomia se faz às custas de nova dependência".

É válido considerar também que, para Lipovetsky, o vazio é também a era da comunicação. Tudo ocorre na comunicação (2005). Mas tal autonomia não fortalece o homem e, quanto mais livre, mais fragilizado. Ou seja: ser livre deixa o homem mais fraco e desestabilizado. Por isso, o homem hipermoderno busca o passado para se encontrar com mais dignidade. (LIPOVETSKY; CHARLES, 2004, p.83-84-85).

Com isso, existe, na hipermodernidade, uma obrigatoriedade de se movimentar, assim há a hipermudança sem o peso de qualquer visão utópica, ditada pelo imperativo da eficiência e pela necessidade da sobrevivência. Não há escolha, não há alternativa, senão evoluir, acelerar para não ser ultrapassado pela "evolução": o culto da modernização técnica prevaleceu sobre a glorificação dos fins e dos ideais (LIPOVETSKY; CHARLES, 2004, p. 57).

Essa ideia será aplicada, nesta produção, especificamente a fim de fazer breve análise dos processos legais assumidos pela gestão e rapidamente encopados por professores e acadêmicos na prática pedagógica da educação superior. 
Quais são esses processos? Como ocorreu essa autonomia? Se toda autonomia existe às custas de outras dependências, como as influências da Covid-19 são entrecortadas pela hipermodernidade na educação superior na Faculdade de Pedagogia da UniRV, a qual, neste trabalho, considerada como espaço ideológico.

\section{A UniRV frente ao distanciamento social e à adesão do ensino não presencial no curso de pedagogia}

A UniRV, locus deste estudo, em defesa da vida humana, e seguida de preocupações de saúde pública, didáticas e pedagógicas, além de, posteriormente, as econômicas, tomou decisões políticas e pedagógicas a fim de deter os avanços da Covid19. Dessa forma, segue registro das as movimentações internas para atender à demanda de uma nova proposta de educação, reinventando-se:

a) Em pronunciamento pelas mídias sociais, na data de 14 de março de 2020, o Prof. Dr. Sebastião Lázaro Pereira, Magnífico Reitor da UniRV, anunciou a Criação de um Comitê Contingencial da UniRV Covid19 para monitoramento da situação e as tomadas de decisões. Tal comitê foi centralizado na Pró-reitoria de Graduação sob a responsabilidade da Prof ${ }^{a}$ Ma. Helemi Oliveira Guimarães de Freitas

b) Em 15 de março de 2020, mediante à portaria 710, da Reitoria da UniRV, as aulas presenciais foram suspensas por 15 dias, a partir do dia 16 de março de 2020; observando assim a declaração da OMS, de 11 de março de 2020 e a Nota Técnica da Secretaria Estadual de Saúde do Estado de Goiás e o Comunicado do Prefeito Municipal do Prefeito Municipal de Rio Verde - GO, em 15 de março de 2020.

c) Em 16 de março de 2020, a Pró-reitoria de Administração e Planejamento, na pessoa do Prof. Me. Alberto Barella Netto, para melhor enfrentamento da pandemia provocada pelo Coronavirus (Covid19), solicitou aos Diretores de Faculdades e Coordenadores de Serviços Gerais e outros Pró-reitores que estabelecessem uma escala de trabalhos dos funcionários, prevendo evitar aglomerações nas repartições. 
d) Por meio da portaria no 002, de 17 de março de 2020 (devido à Covid-19), a Pró-reitoria de Graduação, sob a responsabilidade da Prof $^{a}$ Ma. Helemi Oliveira Guimarães de Freitas, com vistas a evitar prejuízos didáticos e pedagógicos aos acadêmicos, modificou o calendário acadêmico do mês de março, antecipando assim o recesso da Semana Santa para os dias 23 a 28.

e) Em 18 de março, o MEC liberou do ensino a distância por 30 dias e sob foça do decreto no 746, do Prefeito Municipal de Rio Verde - GO, Paulo Faria do Vale e do Procurador do Município Vinícius Fonsêca Campos, Art. 1ํㅡ, declarando "situação de emergência em saúde" pelo prazo de 180 dias, e reforçando em seu inciso $2^{\circ}$ a suspensão dos cursos presenciais, a UniRV começou a otimizar seus trabalhos EAD pelo SEl; adquiriu a assinatura da plataforma ZOOM e, em seguida, 23 de abril de 2020, disponibilizou para os docentes e discentes o pacote de ferramentas tecnológica $G$ Suite, do Google.

f) Juntando aos esforços dos Cursos da área da Saúde da UniRV, para melhor assistir à população rio-verdense, como Enfermagem, Fisioterapia, Odontologia e Medicina - este último nos quatro campi da UniRV, desde o início da suspensão das aulas em 16 de março de 2020 e o alarde da Pandemia em Goiás, a Faculdade de Psicologia disponibilizou a "Escuta Telefônica Emergencial: Covid19", de segunda a sexta-feira, de forma gratuita, pelo telefone 64984058070 .

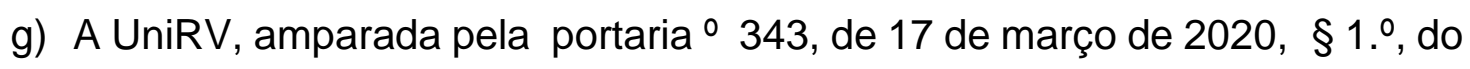
art. $1^{\circ}$ que dispõe sobre a substituição das aulas presencias, por aulas em plataformas digitais, prorrogou por mais 30 dias as aulas não presenciais enquanto durasse a situação de pandemia do Novo Coronavírus - Covid19; em 17 de abril prorrogou para mais 30 dias, sob a mesma recomendação do Ministro de Estado da Educação Abraham Weintraub, ou seja, até 17 de maio; e, em coerência com que reza o Decreta n 109.653, de 19 de abril de 2020 do Governo do Estado de Goiás que dispõe sobre o decreto de situação de emergência na saúde pública do Estado de Goiás, em razão da disseminação do Novo Coronavírus - COVID19. 
h) Até 30 de maio de 2020, as aulas da Universidade foram estabelecidas pelo formato não presencial por meio das plataformas tecnológicas, acompanhando assim a nota técnica a nota técnica da Secretaria de Estado da Saúde no 7/2020 - GAB 0376 que estabelece a prorrogação da interrupção da atividades presenciais em escola até o dia 30 de maio de 2020, assinada por Ismael Alexandrino, Secretário de Estado da Saúde do Goiás e acompanhada pelo decreto № 862, de 20 de abril de 2020, do Prefeito Municipal de Rio Verde, Goiás, Paulo Faria do Vale que, com precisão, no art. 1ํㅡㄹ estabelece situação de emergência em saúde pública por um prazo de 150 dias no município rio-verdense.

i) Neste ínterim, o Comitê Contingencial da UniRV Covid-19 ofereceu tutoriais sobre a Nova Plataforma Suite G - Google, para os docentes e discentes, em 22 de abril de 2020, conforme reconhecido pelo Memorando $\mathrm{n}^{\circ}$ 121/2020, da Pró-reitoria de Graduação. A recomendação era que os docentes e discentes não abandonassem a Plataforma ZOOM e fizessem uso sistemático, para o lançamento das notas e frequências dos acadêmicos e acadêmicas na Plataforma tecnológica SEI, a oficial da UniRV. Portanto, o Google Sala de Aula não substituiu o Zoom, foram utilizadas de forma complementar. As ferramentas institucionais passaram a ser: SEI (apenas para lançamento de notas e frequência); Google Sala de Aula para postagem de materiais, atividades, tarefas, notas, comentários e mensagens; Google Drive (armazenamento de arquivos) e Zoom (aulas virtuais presenciais).

j) Em 23 de abril de 2020, o Comitê Contingencial da UniRV Covid19, em conciliação com o Assessoria de Comunicação da UniRV, disponibilizou no site da UniRV (canto superior), o link para o Google Sala de Aula para os docentes e discentes.

k) Sob a força da Resolução CEE/G) - Conselho Estadual de Educação do Estado de Goiás - n. 07/2020, de 24 de abril de 2020, na qual "Estabelece as normas referentes a estágio e atividades técnicas presenciais no primeiro semestre de 2020 dentro do Sistema Educativo do Estado de Goiás"; tendo em vista os $A r t .1^{\circ}$ e Art. $2^{\circ}$, a UniRV passou a discutir a ideia de 
que os discentes concluintes integralizariam a matriz se houvessem cumprido $75 \%$ da carga horária dos estágios, com aproveitamento, e que estivessem cursando o último período de seu curso, posto que as aulas práticas e laboratoriais poderiam ser mediadas por tecnologia.

I) Como a UniRV possui autonomia acadêmica em nível de Integralização Curricular, amparando-se na Resolução CEE/GO - Conselho Estadual de Educação do Estado de Goiás - ํ‥ 07/2020, de 24 de abril de 2020 e, tendo em vista que cada um dos 22 Cursos da Universidade possui uma especificidade como aulas práticas e laboratoriais, as decisões ficariam a critério de cada Núcleo Docente Estruturante (NDE) e do Colegiado de cada Faculdade, desde que se cumprissem os $75 \%$ da carga horária estabelecida no Projeto Político Pedagógico e Diretrizes Curriculares para o Curso.

m) No que diz respeito aos Estágios Supervisionados do Curso de Pedagogia da UniRV, para a Educação Infantil e Anos Iniciais do Ensino Fundamental, especificamente, no que diz respeito à integralização curricular, em 2020/1, os acadêmicos (as) matriculados no $7^{\circ}$ já haviam atingido a margem de $75 \%$ da frequência aos Estágios Supervisionados nas Escolas Campos, estabelecida pela Resolução n‥ 07/2020, de 24 de abril de 2020, uma vez que, das 400 horas de atividades práticas obrigatórias, 300 já haviam sido cumpridas, com a documentação comprobatória e entregue na Secretaria Geral de Cursos da UniRV ao término do ano de 2019.

n) Gozando da autonomia acadêmica da UniRV, o curso de Pedagogia dispõe do Laboratório Pedagógico Interdisciplinar (LAPEI) /Laboratório Interdisciplinar de Formação de Educadores (LIFE), do Programa Institucional de Bolsa de Iniciação à Docência (PIBID), Residência Pedagógica (RP) do Programa de Consolidação das Licenciaturas (Prodocência) aprovação pela CAPES. A produção teórica dos discentes em elo com estes programas foram convalidadas em Práticas Pedagógicas como Componentes Curriculares, em Atividades Teóricas ou até mesmo horas para completarem os Estágios Supervisionados no que diz respeito a todos períodos do Curso. Com exceção à RP (Residência Pedagógica), o acadêmico do Curso de Pedagogia da UniRV conta com a escola 
campo desde o primeiro período e, com isso, além da experiência que se acumulou, há trabalhos teóricos escritos produzidos por alguns deles. Os programas acima mencionados "objetivam aprimorar a formação inicial dos acadêmicos e permanente dos professores das licenciaturas, dos docentes e gestores das escolas parceiras, por meio da articulação e integração entre o sistema municipal de educação e a IES, contribuindo para a valorização profissional e fixação dos professores na docência" (PPP, 2018, p.77).

o) Nos processos das aulas não presenciais, houve atribuições de notas contínuas e atividades complementares. Essa ação metodológica ocorreu para que os acadêmicos não ficassem prejudicados no que tange ao nível de conteúdo, à metodologia e fundamentos. Além disso, objetivou-se que fosse possível adquirir suporte teórico e prático para desenvolvimento das habilidades e competências para o espaço da atuação profissional na Educação Infantil e Anos Iniciais do Ensino Fundamental.

p) Para esses processos das aulas em $\mathrm{EaD}^{9}$, mediadas por videoconferências, foram convidados os professores (as), preceptores, orientadores e supervisores das escolas campos de estágios. Esses convidados se interagiam com os discentes da Faculdade de Pedagogia da UniRV ao falarem e discutirem assuntos pertinentes às aulas não presenciais das escolas campos, uma vez que, em concomitância com as aulas online da Universidade, nas escolas que são campo de estágio, as aulas também aconteceram à modalidade em EaD. Registra-se que boa parte dos graduandos em Pedagogia está em sala de aula, alguns no Munícipio de Rio Verde e outros em municípios circunvizinhos, ora como professor e professora de apoio, ora como segundo docente, também envolvidos com as aulas online, assim como envolvidos com as aulas não presenciais na

\footnotetext{
${ }^{9}$ Registra-se que essa nova modalidade de educação, motivada pelo distanciamento social devido à necessidade de controlar a Covid-19, não está em total consonância com estatutos que foram legislados para a Educação a Distância, tampouco compreende, na integralidade, o que se prevê na educação presencial, configurando-se assim a modalidade híbrida (misto de EaD e Presencial). À parte às questões contextuais da pandemia no Brasil, esta modalidade híbrida possui amparo legal por meio da Portaria 2.117/2019 do MEC, publicada no Diário, em 11 de dezembro de 2019, que autorizou as instituições de ensino superior (IES) ampliar para até $40 \%$ a carga horária de educação a distância (EAD) em cursos presenciais de graduação.
} 
Faculdade de Pedagogia. Esses encontros por videoconferências foram convalidados como Prática Pedagógica como Componente Curricular e ou Atividades Teóricas.

q) Em 20 de abril de 2020, a UniRV publicou a portaria oㅡ 005 , que altera a portaria no 003 , de 02 de abril de 2020, prorrogando as aulas não presenciais até 30 de maio de 2020. E, de imediato divulgou o novo Calendário Letivo de mês de maio de 2020.

r) Nessa conjuntura da Covid-19, as reuniões com os diretores, alunos e professores, também aconteceram sistematicamente pela plataforma Zoom, em encontros virtuais presenciais.

s) As aulas do Curso de Pedagogia da UniRV foram ministradas pelo Zoom, em aulas virtuais presenciais, observando o horário das aulas previstas para as presenciais. Caso o professor e os acadêmicos (as) assim preferissem, ambos poderiam ocupar o tempo necessário para as orientações metodológicas, didáticas e de fundamentos acerca dos conteúdos teóricos e práticos, mas não eram obrigados (as) a ficarem conectados em tempo real, obedecendo todo o horário destinado às aulas presenciais para as virtuais. O consensual era não ultrapassar o limite de duas aulas, 1h40min; a começar pontualmente às $19 \mathrm{~h}$, até porque os docentes iriam ministrar outras aulas em outras turmas e os discentes teriam aulas com outro professor. Entretanto o término das duas últimas aulas seria às $22 \mathrm{~h} 30 \mathrm{~min}$. Em um eventual tempo insuficiente para aprofundamento dos conteúdos, a esta altura, os acadêmicos (as) já tinham um acesso à Plataforma G Suíte com disponibilidade às diversas ferramentas para coleta dos dados qualificados acerca dos temas das aulas.

t) Como base na Resolução do Conselho Estadual de Educação do Estado de Goiás - CEE/CP n.09, de 30 de maio de 2020 - , no art. 01, em que vem determina "[como medida preventiva à disseminação da COVID-19] que o regime especial de aulas não presenciais e/ou presenciais realizadas por meio de tecnologias, normatizado pela Resolução CEE/CP n. 02/2020 seja estabelecido até o dia 30 de junho de 2020", a Faculdade de Pedagogia, orientada pela Pró-reitoria de Graduação da UniRV, Portaria No 
006, de 1ํ de Junho de 2020, estabelece que as aulas continuariam remotas e seriam ministradas até 31 de junho de 2020, endossando assim as s decisões do Colegiado de Pedagogia como: os professores e acadêmicos que fecharem a carga horária da disciplina, bem como as notas, estariam dispensados a partir de 15 de junho de 2020. Registra-se que tanto os professores quanto os acadêmicos que ainda se encontrassem em pendências nesses itens, teriam até o fim do primeiro semestre letivo para sanarem essas pendências, utilizando-se sempre das plataformas Sei, Zoom e Google Sala de Aula ${ }^{10}$.

Esses caminhos percorridos mostram a urgência de movimento da instituição de ensino superior UniRV frente ao distanciamento social, na crise sanitária, e que a ressignificação da prática pedagógica não foi apresentada como opção. Nisso, constituíram-se as influências da Covid-19, uma vez que houve aceleração desse processo que já estava sendo instaurado ${ }^{11}$ nos sistemas educacionais.

\section{4. $O$ curso de pedagogia da UniRV atento aos desafios no contexto da modernidade, da pós-modernidade em transição para a hipermodernidade}

O Curso de Pedagogia, oferecido pela Universidade de Rio Verde, iniciou-se no ano de 1973, oferecendo a licenciatura curta ${ }^{12}$. Em de 13 de janeiro de 1984, o referido curso de graduação migrou para licenciatura plena ${ }^{13}$ (PPP, 2018, p. 12-18).

A partir de 1993, a Habilitação para o Magistério das Disciplinas Pedagógicas do $2^{\circ}$ grau e para as séries iniciais do Ensino Fundamental foram incorporadas ao curso e, a partir de então, foram oferecidas 30 vagas para cada semestre letivo no contexto da matriz de número 45.

\footnotetext{
${ }^{10}$ Considerando a necessidade de conter a propagação de infecção e transmissão local e preservar a saúde dos servidores, docentes e da comunidade em geral, a gestão superior da UniRV, por meio da portaria $n^{\circ} .1 .303$, de 23 de junho de 2020 , resolve, prorrogar em caráter excepcional, o prazo previsto no artigo $1^{\circ}$ da Portaria - PROGRAD №. 006/2020, a fim de estabelecer que, o regime especial de aulas não presenciais mediadas por tecnologias, poderá ser estendido até 31 de dezembro de 2020.

${ }^{11}$ Antes da Covid-19, era lento e gradual.

${ }^{12} \mathrm{~A}$ integralização curricular era em 2 (dois) anos).

${ }^{13} \mathrm{~A}$ integralização curricular passou para 4 (quatro) anos.
} 
Em 1999, entrou em vigor a matriz 19 com Habilitação para Magistério de disciplinas do $2^{\circ}$ Grau e para as séries iniciais do Ensino Fundamental. Em 2007, na matriz 64, foram incluídas as disciplinas comuns em um núcleo, denominado Núcleo de Disciplinas Comuns (NDC).

Em 2008, o curso de Pedagogia passou a oferecer 60 vagas, antes 30 . Em 2010, no primeiro semestre de 2010, iniciou-se o curso por meio da Matriz 107, o destaque dessa matriz se refere à passagem da hora-aula de 50 minutos para 60 minutos e ao aumento da carga horária dos Estágios nos Anos Iniciais do Ensino Fundamental para $400 \mathrm{~h}$, antes $380 \mathrm{~h}$, e antes destas $120 \mathrm{~h}$. Registra-se que os Estágios de campo aumentaram de 3 para 6 horas ${ }^{14}$.

Devido à necessidade de atendimento às normas estabelecidas para atualização da formação de professores no país, especialmente a Resolução № 2 de $1^{\circ}$ de julho de 2015, houve a alteração da matriz 107 para a 169. Esta definiu as Diretrizes Curriculares Nacionais para a formação inicial em nível superior (cursos de licenciatura, cursos de formação pedagógica para graduados e cursos de segunda licenciatura) e para a formação continuada.

Essa matriz 169 passou a ser denominada, em 2017, como matriz 186, tendo como foco centrar na formação didático-pedagógica dos acadêmicos em prol do fortalecimento das teorias e das práticas em sala de aula. Entretanto, nessa mudança, as disciplinas Filosofia e Sociologia foram oferecidas a fim de contribuir para a formação de professores críticos e reflexivos no contexto da sala de aula. Registra-se que as disciplinas Filosofia e Sociologia estiveram ausentes do histórico do Curso de Pedagogia da UniRV, licenciatura plena, tão somente um ano, em 2015, desde 1984.

Entre os anos de 2017 a 2019, a gestão superior da UniRV colocou em discussão a proposta das aulas no âmbito das metodologias ativas; convocando o corpo docente para seminários voltados para as aulas virtuais, vislumbrando que as tecnologias digitais são tendências em ascensão nos campus da UniRV.

Neste ínterim, no Curso de Pedagogia da UniRV, os diálogos começaram, tendo como ponto de partida a ideia de que a próxima matriz em vigor deveria ser

\footnotetext{
${ }^{14}$ AS aulas teóricas não sofreram alteração em nível de carga horária, salvo quanto à nomenclatura, como se segue - Estudos e Pesquisas Pedagógicas nos Anos Iniciais do ensino Fundamental I e II, Estudos e Pesquisas Pedagógicas na Educação Infantil I e II.
} 
declinada para o Ensino Híbrido. Para isso, o essencial era a alteração das metodologias do curso uma vez a UniRV adotou uma política de implantação das tecnologias digitais em todos os campus.

O propósito das disciplinas híbridas foi pautado na ideia de motivar 0 protagonismo dos discentes frente às novas tecnologias, despertando-os para a autonomia diante do próprio interesse pelo aprendizado e oferecer ao estudante 0 protagonismo da própria formação.

\section{Elos da modernidade com pós-modernidade em direção à hipermodernidade nos fins}

As alterações das matrizes ocorridas há mais de 37 anos, de licenciatura curta com 02 (dois) anos, para licenciatura plena de 04 (quarto) anos, fazem parte da otimização dos Projetos Pedagógicos por forças das circunstâncias históricas e legais.

Entretanto, é visto que os sujeitos envolvidos nesta conjuntura vivenciam uma característica desconcentrada e heterogênea, inovadora e anacrônica, sofisticada e irrefletida, espetaculosa e inventiva, dualista em uma conivência sutil de contrários; de um individualismo elevado em prol da negação da modernidade, aproximando-se se assim da pós-modernidade, com forte afago à prática do narcisismo, como diria Lipovetsky (2005, p. 92). Os sujeitos envolvidos fazem parte da transição dos valores da modernidade ${ }^{15}$, a pós-modernidade ${ }^{16}$, em direção a hipermodernidade.

Ao iniciar a formação de professores, em 1973, em licenciatura plena, o curso propunha a formar supervisores e administradores em educação e formar professores para o magistério. Em 1987, vieram as Habilitações em Administração e Supervisão Escolar, e, durante 11 anos, fora implantada nova estrutura curricular, passando para licenciatura plena, o que aconteceu em 1984 (PPP 2018, p.12).

\footnotetext{
15 "refere-se a estilo de vida ou organização social que emergiram na Europa a partir do século XVII e que ulteriormente se tornaram mais ou menos mundiais em sua influência" (GIDDENS, 1991, p. 11).

${ }^{16}$ A sociedade capitalista contemporânea se desgasta com as críticas às grandes narrativas do iluminismo, às chamadas metanarrativas, às ideologias sustentadoras das revoluções do século XIX, à aceitação literal das regras das ciências e à operacionalização das instituições modernas (LYOTARD, 2020, p. 12).
} 
Observa-se que há uma transição do foco iniciar que era formar supervisores e administradores para habilitá-los a ações concretas dentro do espaço escolar. Embora valorizando o individualismo, essas mudanças desfazem das questões políticoideológicas, valorizam as inconstâncias apressadas das autoridades em desfavor das ações colegiadas e coletivas.

É a era do vazio sendo consumada, refletida nos processos de personalização dos indivíduos que influenciam a sociedade. O indivíduo, antes aberto; livre, é formado a se tornar objeto de massa, mesmo desempenhando funções particularizadas. Esse processo o leva a um comportamento narcisista porque é seduzido a ser "um melhor" se especializando, a comportar-se como indiferente diante dos desafios do seu semelhante e a se tornar um consumista porque para ser firmar como bom profissional é necessário atender padrões de exigências das unidades de ensino.

Com isso, configura-se a era do pós-moderno em vigor, rompendo com o estado moderno que se caracterizava pelo apego às verdades científicas, às constantes revoluções contrárias às práticas feudais de domínio e do peso das tradições.

\footnotetext{
O modernismo não é uma ruptura primeira e incomparável: na fúria de destruir a tradição e inovar radicalmente, o modernismo prossegue na ordem cultural, com um século de intervalo, a obra própria das sociedades modernas visando instituir a democracia. O modernismo não é mais do que uma face do vasto processo secular que conduz ao surgimento das sociedades liberadas da submissão dos deuses, das hierarquias hereditárias e do domínio da tradição (LIPOVETSKY 2005, p. 66).
}

Nessa passagem, constata-se que a modernidade vai se se dissolvendo aos poucos em seus valores e, por mais que ela queira inovar-se, mais ao posso que se atenda a isto, não se firma em uma única visão, ou seja, em suas verdades absolutas sustentadas pelas ciências.

No curso de Pedagogia da UniRV, essa transição se torna perceptível de uma matriz para outra, a dissolução de um valor, de um objetivo e detrimento ou novo é inevitável. Como se fosse passar dos valores defendidos pela modernidade, rumo a pós-modernidade para a vivência de uma hipermodernidade.

Vê-se que, em 1993, houve a oferta do curso de anual para o semestral com 30 Habilitação para o Magistério das Disciplinas Pedagógicas do 2o grau 
somando ao curso a Habilitação Magistério para as séries iniciais do Ensino Fundamental. Em 2007, são inseridas disciplinas do núcleo comum como Língua Portuguesa, Filosofia, Sociologia Ética; em seguida as Habilitações ${ }^{17}$ são extintas e a nova matriz 64/107 objetiva capacitar o futuro licenciado para atuar na Educação Infantil, nos Anos Iniciais do Ensino Fundamental, em área de serviços e apoio escolar e em outras áreas nas quais sejam previstos conhecimentos pedagógicos, ou seja, ser profissional em contextos escolares e não escolares (PPP 2018, p. 12-13).

O curso acompanha transição da modernidade para a pós-modernidade, com valores da hipermodernidade. O indivíduo, nesse processo, dentro da escola, busca se harmonizar; é induzido a ser íntegro em situação de dissociabilidade de valores tradicionais, remetendo-se ao processo de personalização em que conviver com a incorporação de novas estratégias na prática pedagógicas são decisões que precisam ser aceitas por si mesmo, porque estas múltiplas questões lhe pertences e estão sob o seu domínio, mas que não lhe são perenes. Nas palavras de Gilles, isso diz respeito a

[...] nova maneira de a sociedade se organizar e se orientar, novo modo de gerenciar os comportamentos, não mais pela tirania dos detalhes, mas com o mínimo de constrangimento e o máximo possível de escolhas privadas, com o mínimo de austeridade e o máximo possível de desejo, com o mínimo de coerção e o máximo de compreensão (LIPOVETSKY, 2005, p. 16).

Dessa forma, o indivíduo se sente livre porque não é mais submisso às regras. Ele tem o direito de ser ele mesmo; entretanto, deve observar as suas escolhas privadas com o máximo de compreensão. O indivíduo se torna mais livres, só que comprometido em o seu desempenho ora como formando, ora como formador. O que se nota é que:

Uma nova geração de sociedades burocráticas e democráticas faz sua
aparição, com dominante "leve" e frívola. Não mais a imposição coercitiva das
disciplinas, mas a socialização pela escolha e pela imagem. Não mais a
Revolução, mas a paixonite do sentido. Não mais a solenidade ideológica,
mas a comunicação publicitária. Não mais o rigorismo, mas a sedução do
consumo e do psicologismo. [...] A moda consumada não significa
desaparecimento dos conteúdos sociais e políticos em favor de uma pura
"gratuidade esnobe", formalista, sem negatividade histórica. Significa uma

17 Pois atendiam um caráter racionalizante dentro dos processos pedagógicos do curso de formação de professores. 
nova relação com os ideais, um novo investimento nos valores democráticos e, ao mesmo tempo, aceleração das transformações históricas, maior abertura coletiva à prova do futuro, ainda que nas delícias do presente (LIPOVETSKY, 2009, p. 180-181).

"À prova do futuro, ainda nas delícias do presente", o Curso de Pedagogia da Universidade de Rio Verde é impulsionado a se apropriar das tecnologias digitais em meio à Covid19 na vigência uma matriz de cunho presencial, matriz 186, que tem por finalidade formar licenciados em Pedagogia para atarem na Educação Infantil e Anos Iniciais do Ensino Fundamental conduzido por um corpo docente qualificado para as aulas presenciais.

Uma realidade inesperada se apresenta ao indivíduo. O abalo não vem somente na crítica à supremacia da ciência como detentora da verdade, ou no declínio das ideologias de cunho política de esquerda ou de direita, ou na escolha da tendência pedagógicas tradicional ou progressista.

Esse abalo advém de uma forma nova de lidar com as metodologias, os fundamentos de ensino impulsionados pelo imperativo do momento: orientar aos alunos (as) e aos professores a se inerirem em uma cultura "hiper". Sem exceção, todos são impelidos a investirem em Internet via rádio, Internet móvel, Internet via cabo, Internet fibra óptica ou Internet via satélite.

Ao se lançar nas plataformas digitais, o indivíduo começou a presenciar a sua própria imagem porque necessita manter interlocução com própria imagem até então era vista, por si mesmo, no momento em que participava de aula online ou aula não presencial. Portanto, durante1h40min, enquanto o professor estiver ministrando a aula remota, ele está sujeito a se ver pelas câmeras dos aparelhos celulares, do seu próprio computador.

Ficando em casa para estudar, trabalhar ou não trabalhar, o aluno e ou o professor se envolveu no consumo de produtos em excesso, mediante as propagandas virtuais. Nesse processo, as instituições de ensino foram levadas a adquirirem hiperplataformas, para atender hipernúmeros de professores e alunos ao mesmo tempo. Estes, por sua vez, ficam vulneráveis às hiperempresas que desejam vender os seus produtos como se fossem hiperprodutos com a promessa a garantirem melhores instruções, lazer e segurança pessoal a se assim forem consumidos. 
Posto isto, denota-se que a hipermodernidade não se caracteriza somente pela não institucionalização, pelo descarte da tradição, pelo não incentivo às discussões revolucionárias ou pelo prazer imediato aos feitos realizados; mas também se caracteriza pelo hiperconsumo, hipernarcisismo, hipercapitalismo e hiperindividualismo (Lipovetsky \& Charles, 2004, p. 55- 56).

\begin{abstract}
Para o filósofo, vivemos uma época de reviravoltas e avanços na técnica e na ciência de um lado, porém, de outro, claramente empobrecida no âmbito cultural. A hipermodernidade desencadeou a derrocada das esperanças de revolução, a derrubada das importantes aspirações sociais e políticas e a desvalorização dos valores universais, tendo - os como longínquos, generalistas, incompreensíveis (LIPOVETSKY \& CHARLES apud BRITO, p. 173-174)
\end{abstract}

A hipermodernidade, no âmbito do curso de Pedagogia da UniRV, suscitou, à maneira inesperada, um comportamento instantâneo no preparo e participação das aulas. Todos os envolvidos foram levados a produzirem e lidarem com os hipertextos, ou seja, com "a coprodução de cultura no universo digital, [em que] não existe autores e leitores textuais, mas debatedores de temas e estes debates geram a cibercultura (SANTOS; PAIXÃO, 2016, p.05).

Neste interim, palavras novas são incorporadas cotidianamente ao meio acadêmico como: Quarentena, Pandemia, Trabalho Remoto, Live, Lockdown, Drivethough, Plataformas digitais Zoom, Meets, G Suíte, Classroom, entre outras; e, com isso, também muda o agir didático, pedagógico e metodológico do Professor do Curso de Pedagogia como bem sintetiza a Prof ${ }^{a}$ Alacoque Lorenzini Erdmann, em um texto adaptado, enviado pelo WhatsApp para um grupo de amigos, em 11 de maio de 2020:

De um dia para o outro, os professores, montaram todo um sistema de educação obrigatória à distância, para continuar a prestar a sua missão de vida a partir de casa... Com mística e dedicação...

Materiais? Seu computador, privado e pessoal; e sua internet ... paga do próprio bolso.

Espaços? O salão de sua casa, que torna pública a desconhecidos a intimidade de sua casa.

Direitos autorais? Cedidos, pesquisas, imagem, textos, tarefas...

Exigências? Absolutas. Reclamações de todos a todo momento, sem sensibilidade alguma ao esforço súbito a que estamos submetidos!

A escola na sala de casa nunca acaba.

Um milhão de e-mails para atender... grupos pelo WhatsApp, chamadas, atendimento personalizado, aproximando-se da função tutorial...

reuniões a qualquer hora, mensagens de toda ordem... 


\title{
ISSN: 2675-682X Dossiê Temático COVID E INTERDISCIPLINARIDADE
}

Gestores, Alunos, Famílias, Sociedade, nós professores estamos trabalhando... $\mathrm{Na}$ verdade multiplicamos por muito as nossas horas de trabalho, pois agora esclarecemos as dúvidas um a um, corrigimos as tarefas uma a uma, sem acréscimo salarial ou mero reconhecimento ou agradecimento por isso... Nos doamos para além do conteúdo, sem falar sobre as orientações de ordem psicológica, dentro da compreensão de fazer com que os nossos alunos vejam a transcendência do que estamos experimentando...

NÂO HAVERÁ APLAUSOS PARA OS DOCENTES!

Mas eu aplaudo os professores! Eu aplaudo os meus colegas. Eu aplaudo os professores com todas as minhas forças! Por brindar à educação o lugar que Ihe cabe nesta época de crise...

Fazemos parte da história... Ainda que não sejamos aplaudidos, eis aqui um milhão de aplausos para todos nós!

Essa atmosfera de hipermodernidade, construída e reconstruída em que tudo é imediato e se dissolve em seguida, em prol na continuidade do ano letivo na Universidade de Rio Verde-UniRV, as aulas não presenciais, por meio de plataformas digitais, são realizadas.

Essa reinvenção quanto ao espaço de trabalho, a plataforma, perspectiva pedagógica e interação com o acadêmico foi se encorpando na instituição-foco, ao passo que os docentes e acadêmicos entenderam rapidamente e já mobilizaram forças para fazê-la real e sem muito estranhamento. Sobre esse impulso, Lipovestsky assegura que, na hipermodernidade, importa é viver a descoberta ou a evasão, desde que se confronte algumas representações sociais, nesse caso, a própria instituição educação, buscando assim romper ${ }^{18} \mathrm{com}$ aquilo que, ao longo dos anos, foi posto como condição de trabalho. (LIPOVETSKY; CHARLES, 2004, p.21).

Essa nova possibilidade ganhou espaço devido às tecnologias digitais, sobre as quais é possível destacar que:

\begin{abstract}
O processo de conquista novos setores e vai atingir uma extensão (ainda difícil de imaginar) com as novas tecnologias com base nos microprocessadores e nos circuitos integrados. Já existem no ensino: trabalho independente, sistemas operacionais, programas individuais de trabalho e auto-apoio por microcomputadores; estabelecimento, dentro de prazo mais ou menos longo, do diálogo on-line, da auto-avaliação, da manipulação pessoal da informação. (LIPOVETSKY, 2005, p. 4)
\end{abstract}

\footnotetext{
${ }^{18}$ Não se pretende, nesta produção, tratar sobre a $\mathrm{EaD}$ uma vez que já é instituída pela legislação educacional brasileira. Busca-se, portanto, trazer para o escopo a discussão acerca de como a instituição educacional presencial de educação superior migrou para uma nova modalidade ao passo que essa reinvenção tenha ocorrido de forma quase instantânea, reinventando-se.
} 
Então, o que define a hipermodernidade não é "[...] exclusivamente a autocrítica dos saberes e das instituições modernas; é também a memória revisitada, a remobilização das crenças tradicionais, a hibridização individualista do passado e do presente" (LIPOVETSKY; CHARLES, 2004, p.98). Na instituição observada, não houve imediato desprendimento total da educação presencial, isto é, foram mantidos os turnos das aulas, os horários dos professores e das disciplinas ao passo que se tornou uma educação híbrida, composta pela reinvenção da presencial, todavia, por meio dos recursos tecnológicos próprios da modalidade a distância, respeitando as normas de distanciamento social.

Para garantir essa nova modalidade de ensino, foi preciso acionar outras potencialidades dos sujeitos hipermodernos como a autogestão. Segundo Lipovestsky, esse autogerenciamento objetiva "[...] suprimir os relacionamentos burocráticos do poder, em fazer de cada qual um sujeito político autônomo" (2005, p. 10) apto a ser gerido agora pela sedução ${ }^{19}$.

Assim, cada sujeito da educação superior (reitoria, docente e acadêmico), imbricado pela autonomia inerente ao momento em que as estruturas estabilizantes, como o prédio da universidade, sala de aula, interação presencial, corpo a corpo; currículo; metodologia e aprendizagem mediante relações interpessoais foram destituídas, mas ,imediatamente, houve necessidade de nova dependência. Esta, por sua vez, precisou se reestruturar com urgência para suprir o vazio da desterritorialização. Esse advento é o que Lipovetsky (2005, p. 3) chama de sedução, pois cada ser, instituição inicia o processo de composição da sua existência.

No âmbito da Faculdade de Pedagogia, esse apontamento do filósofo francês consiste na autonomia por que cada esfera estruturante da educação (Estado, Município, Reitoria) precisou rearticular para que, na prática, o ensino aprendizagem pudesse continuar, mas em plataformas virtuais.

Eis aí as ocupações da Faculdade de Pedagogia em um contexto de hipermodernidade frente à Covid19.

\footnotetext{
19 "Sedução no sentido em que o processo de personalização reduz os quadros rígidos e coercitivos, funciona com suavidade respeitando as inclinações do indivíduo, seu bem-estar, sua liberdade e seus interesses" (LIPOVETSKY, 2005, p. 3)
} 


\section{Considerações finais}

Assim, mediante o distanciamento social e, com as novas tecnologias, a autonomização do sujeito e da instituição aumentou, ganhando novas autonomias em relação ao tempo coletivo o que resultou na dessincronização das atividades e ritmos peculiares e o indivíduo hipermoderno, aos poucos desinstitucionalizado, buscou se renovar em sua subjetividade.

Todavia, ressalta-se que essa transposição da aula presencial para a não presencial, na UniRV, ocorreu ao passo que se buscou manter a essência da primeira e os meios da segunda, gerando o referido hibridismo. Lembrando que essa questão apresentou também certo incômodo, posto que os sujeitos hipermodernos são, ao mesmo tempo, mais informados, mais abertos e receptivos, mas também mais desestruturados e mais instáveis. Isso significa que, por meio da sedução, esses sujeitos buscaram se adaptar, mas também passou haver ansiedade, dúvidas e insegurança em relação ao processo pedagógico em si.

Dessa forma, parafraseando Sebastião Lázaro Pereira, popularmente conhecido por |Prof. Tatão, Reitor da Universidade de Rio Verde, o ensino híbrido é legado da pandemia para educação (PEREIRA, 2020, [s/p]). Torna-se evidente que as plataformas digitais vieram para ficar e comporão a tecnologia que passará ser auxiliar toda a dinâmica educacional daqui para frente.

Ainda, segundo o Reitor, em discurso responsivo ao ideário hipermoderno, o ser humano resiste, mas em caso de necessidade, reage com aceitação e se adapta com facilidade. Foi isso que ocorreu em relação às tecnologias na educação híbrida do período de pandemia, isto é, tanto alunos quanto os docentes estranharam, mas logo se adaptaram.

"O vírus não vai sumir", disse Pereira (2020, [s/p]) em entrevista concedida ao Jornal Opção. Afirmou ainda que o ensino híbrido "veio para ficar" e que essa absorção da tecnologia é, certamente, muito importante nesse momento histórico em que se estabelece um marco educacional no ensino superior.

Portanto as influências da Covid-19 foram invasivas e determinantes, entrecortaram os valores da hipermodernidade, sedimentando essa essência da UniRV que, como instituição de educação, interage ativamente e também 
reage a questões sociais, políticas e sanitárias do país, reinventando-se.

Hiperinventando-se.

\section{REFERÊNCIAS}

BRITO, Wallace da Costa. Os conceitos pós-modernidade e hipermodernidade em Gilles Lipovetsky. UFRRJ - Perspectivas em Psicologia: Volume 19, N. 2, pp. 155 - 182, Jul/Dez, 2015.

ERDMANN Alacoque Lorenzini. Não haverá aplausos para os docentes, WhatsApp: [Grupo do CEMMG]. 9 de maio de 2020. 18h22min. 1 mensagem de WhatsApp.

GIDDENS, Anthony. As Consequências da Modernidade. São Paulo: Unesp, 1991.

LIPOVETSKY, Gilles. A Era do Vazio: ensaios sobre o individualismo contemporâneo. Trad. Juremir Machado da Silva. Barueri - SP, Editora Manole, 2005.

LIPOVETSKY, Gilles. O império do efêmero: a moda e seu destino nas sociedades modernas. São Paulo: Cia das Letras, 2009.

LIPOVETSKY, Gilles; CHARLES, Sébastien, Os Tempos Hipermodernos. Trad. Mário Vilela. São Paulo: Editora Barcarolla, 2004.

LIPOVETSKY, Gilles; SERROY, Jean. A Estetização do Mundo: viver na era do capitalismo artista. Trad. Eduardo Brandão. Rio de Janeiro: Companhia das Letras, 2009.

LYOTARD, Jean-François. O Pós-Moderno. Rio de Janeiro: José Olympio, 2002

SANTOS, Gilmar Fabiano da Silva; PAIXÃO Waldeia do S. Bastos Paixão. A PARALINGUAGEM NAS PLATAFORMAS DIGITAIS. In: o 9 Encontro Internacional de Formação de Professores /10 Fórum Permanente de Inovação Educacional / II Encontro Estadual de Sergipe da Associação Nacional pela Formação dos Profissionais da Educação (Anfope). Sergipe, v. 9, n. 1, 681 (1-12) maio/2016 Disponível em: < https://eventos.set.edu.br/index.php/enfope/article/view/1821/681> Acessado em 10 de maio de 2020.

PEREIRA, Sebastião Lázaro. Ameaçadas, faculdades privadas resistem à crise e encontram saída na tecnologia. Jornal Opção, Goiânia, domingo, 31 de maio de 2020. Disponível em <https://www.jornalopcao.com.br/reportagens/ameacadasfaculdades-privadas-resistem-a-crise-e-encontram-saida-na-tecnologia-257741/ >

Acessado em 01 de junho de 2020.

UNIVERSIDADE DE RIO VERDE. Projeto Político Pedagógico do Curso de Pedagogia. Rio Verde: 2018. 
Manuscrito recebido em: 16 de dezembro de 2020

Aprovado em: 30 de dezembro de 2020

Publicado em: 30 de dezembro de 2020 